\title{
Synthesis and Characterization of Alumina-Chitosan- Hydroxyapatite Biocomposites for Load Bearing Application
}

\author{
Abere D.V. \\ National Metallurgical Development Centre, Jos, Nigeria \\ Oyatogun G.M. \\ Oluwasegun K.M. \\ Ayodele T.J. \\ Department of Materials Science and Engineering, \\ Obafemi Awolowo University, Ile - Ife, Nigeria \\ Ajayi S.V. \\ Ohwoekevwo J.U. \\ Adejo O.H. \\ National Metallurgical Development Centre, Jos, Nigeria
}

Doi: 10.19044/esj.2018.v14n30p145 URL:http://dx.doi.org/10.19044/esj.2018.v14n30p145

\begin{abstract}
This study investigated the influence of reinforcing hydroxyapatite (HA) with alumina ( $\mathrm{Al})$ and chitosan nanofiber $(\mathrm{CH})$ to enhance its usefulness in load bearing application. Commercial alumina was used while chitosan fiber and hydroxyapatite were synthesized from cowry shells and limestone respectively. The developed composites were characterized with a view to assessing their suitability for use as medical implants in load bearing capacity. It was observed that the optimum compressive strength obtained was 181.73 $\mathrm{MPa}$, tensile strength of 172.67 MPa, hardness value of 529.21 HV, fracture toughness of $7.42 \mathrm{MPa}^{1 / 2}$, elastic modulus of $8.23 \mathrm{GPa}$ and bending strength of $175.51 \mathrm{MPa}$. Increasing volume fractions of $\mathrm{Al}-\mathrm{CH}$ resulted in decrease in compressive strength, hardness and elastic modulus of hydroxyapatite while its tensile strength, bending strength and fracture toughness increased. The result obtained from the Fourier Transform Infrared Spectrometry revealed that the intermolecular hydrogen bond and chelate interaction between the constituents contribute to the good mechanical properties of the composite. X-Ray Fluorescence analysis result indicates that their chemical compositions contain ions which are found in the physiological environment. The dispersion of the alumina-chitosan nano fiber in the HA matrix as revealed by the Scanning Electron Microscope micrographs result
\end{abstract}


in the formation of interfaces which activates different mechanisms that improve the strength of HA. The optimum mechanical property was obtained at 20-20-60 Al-CH-HA composite. Hence, this composite will be a suitable material for load bearing application.

Keywords: Hydroxyapatite, Alumina, Chitosan nanofiber, Al-CH-HA composite, Load bearing application

\section{Introduction}

Among the major human health challenges encountered in our day to day activity are organ and tissue failures due to an injury or disease. This may result in total loss of such organ. Consequently, urgent therapy is needed to restore the tissue, or organ that has lost its function. Organ or tissue transplant is a standard therapy to treat affected patients. This is however, limited as a result of the shortage of donor and adverse immunological response. Other therapies include drug therapy, surgical reconstruction, synthetic prostheses and medical devices are also fraught with diverse limitations which include the need for lifelong immune suppressant, inability of device to replace all the functions of a damaged or lost organ, stress shielding, etc. Tissue engineering has therefore been a great substitute for the treatment of malfunctioning or lost organs.

In tissue engineering, a scaffold is required to function as an adhesive substrate for the implanted cells as well as providing physical support to aid the formation of the organs to be formed. Also, the scaffold for tissue engineering should be mechanically competent in order to enable it to allow the retention of differentiated cell functions. For example, the mechanical properties of the scaffolds should be strong enough to provide mechanical strength in load bearing sites before the regeneration of new tissue. In bone regeneration a suitable scaffold is expected to be bioactive, that is, allow the adsorption, consequently, adhesion and proliferation of bone cell. (Langer et al., 2004; Wang et al 2010). Hydroxyapatite is a typical example of bioactive materials (Park et al., 2001).

\section{Hydroxyapatite}

Hydroxyapatite is among the major mineral constituents of bones, it has excellent biocompatibility. It is also among the few materials that are classed as bioactive materials because of its excellent osteoinductive and osteoconductive attributes (Park et al., 2001). Subsequently, it will enhance bone in growth and osseointegration when employed in orthopedic, dental and maxillofacial applications (Kattis 2004).

It has been reported by several researchers that there are various natural biocomposites. The biocomposites are engineered from organic matrix and 
inorganic fraction and meet the mechanical properties requirement in their functions as the skeleton, teeth or shells of organisms (Ratner, 2004). For example, organic collagen mixed with inorganic hydroxyapatite [HA: $\left.\mathrm{Ca}_{10}\left(\mathrm{PO}_{4}\right)_{6}(\mathrm{OH})_{2}\right]$ in bone and chitin is associated with calcium carbonate in crab shell (Shahidi and Abuzaytoun, 2005). These compositions possess good mechanical properties and are suitable to withstand tremendous pressures (Wang et al., 2001). Hydroxyapatite has been used in a wide variety of oral and maxillofacial applications because of its good attributes of properties such as hardness, biocompatibility, osteoconductivity, a certain degree of bioactivity, and high resistance to moisture (Sono, 2003). The versatility of hydroxyapatite as part of biocomposites enables materials engineers to combine materials with various degrees of biocompatibility to produce satisfactory biomaterials for a certain application in the body. Its availability is in dense blocks, porous blocks, and granules. However, there are drawbacks in each of the forms; for example, dense hydroxyapatite is not easy to machine without resulting to large-scale fracture, granules tend to migrate, and the macroporous material leaves a rugged surface finish.

Limestone is an industrial mineral and rock with a chemical composition of $\mathrm{CaCO}_{3}$. It belongs to the carbonate minerals based on the $\mathrm{CO}_{3}{ }^{2-}$ ions. Limestone is rich in calcium which is among the prominent constituents of hydroxyapatite. Most limestone is product of the calcareous skeletons of organisms like corals, mollusks and foraminifera.

Generally, dense hydroxyapatite does not possess the mechanical properties requirement to enhance its usefulness in long term structural applications; consequently, the need to improve its strength to make it suitable for load bearing application. One of the approaches to accomplish this is by incorporating alumina and chitosan nanofiber into its matrix. The aim of creating alumina chitosan composite is to improve the mechanical strength of hydroxyapatite.

\begin{abstract}
Alumina (Al)
Biocompatible ceramics with mechanical properties comparable to metals are preferred in parts of the body that have high wear risk. An inert ceramic, alumina is used in load bearing hip prosthesis and dental implants in dense and pure state because of its excellent corrosion resistance, high strength and high wear resistance. Alumina's long term use in orthopedic surgery has been motivated by its excellent biocompatibility and formation of very thin capsule which permits cement less fixation of prostheses as well as its very low coefficients of friction and wear. The exceptional tribologic properties of alumina are due to small grain sizes less than 4 microns and narrow grain size distribution which lead to very low surface roughness. Rapid wear of bearing
\end{abstract}


surfaces occurs when there is large grain due to grain pull out as a result of local dry friction.

As a mechanically strong ceramic alumina, is also applied as a material for reinforcement in biocomposites. Strength, resistance to fatigue and fracture toughness of polycrystalline alpha alumina are functions of grain size and purity. Suitable flexural strength, excellent impact and dynamic fatigue resistance, subcritical crack growth resistance and excellent compressive strength are obtained with average grain sizes < 4 microns and purity $>99.7$ $\%$ (Ratner et al. 2004). Clinical applications of alumina include knee prostheses, bone and dental screws, alveolar ridge, reconstruction of maxillofacial, ossicular bone substitutes, corneal replacements and segmental bone replacements.

\section{Chitosan (CH)}

Chitosan is a deacetylation product of chitin which is a functional and basic polysaccharide which is made up of b-1, 4-linked glucosamine, which could be extracted easily from exoskeletons of shrimps and crabs (Park et al., 2001). Owing to its unique properties like nontoxicity, biodegradability, biocompatibility and antimicrobial activity, much attention is being given to chitosan for applications in biosensing, medical and pharmaceutical (Suzuki et al., 1998; Vande Vord et al,. 2002; Luo et al., 2005). Also, it is one of the most useful natural polymers in regenerative medicine and tissue engineering (Langer et al., 2004). Chitosan nanofibers have as well been applied as materials in biomedical scaffolding for the purpose of restoring, maintaining or improving the functions of different tissues (Nam et al., 2010; Jayachandran and Kim, 2010).

Chitosan is produced from chitin, being a natural polysaccharide found in crab, shrimp, cowry shell, lobster, coral, jellyfish, butterfly, ladybug, mushroom and fungi. Also, shells of the marine crustacean are utilized widely as the main sources of producing chitosan (Madhavan and Nair, 1974; Shahidi and Abuzaytoun, 2005). Cowry shells are among the important marine species of great commercial importance in the tropical and subtropical waters of the Pacific, Atlantic and Indian Oceans. Calcium is the most abundant mineral present in the perforated cowry shells. The high content of calcium confirms its medicinal role in bone formation. It was reported that the cement of the cowry shell could be applied as possible cement for bone formation (Fish and Fish, 1996) and are used as calcium supplement. Iron, aluminum and sodium are found in reasonable amount. The wastes from cowry shells have recently become a serious issue in coastal areas. The extraction of bioactive material from these wastes is the easiest means of reducing pollution. It not only reduces the environmental pollution because of the disposal of this under utilized by-products of cowries but also increases the potential applications of 
chitosan. Moreover, the enzymatic and chemical hydrolysis methods being used widely for the extraction of chitosan from the shells of the marine crustacean are quite inexpensive.

\section{Chitosan composites}

Chitosan composite materials with their applications in bone tissue engineering have attracted great attention in previous years. This may be ascribed to its non toxicity, intrinsic antibacterial attribute, biocompatibility, biodegradability and the ability to be molded into difference geometries and forms (Luo et al., 2005). Such form includes porous structures, suitable for cell in growth and osteoconduction. Composite of chitosan and other material are becoming popular due to their biocompatibility and biodegradability. Chitosan composites are thus emerging as potential materials for artificial bone and bone regeneration in tissue engineering (Langer et al., 2004).

Research on chitosan composites for hard tissue applications have been on for about 4 to 5 years. Although bioresorbable composite devices other than chitosan have been in clinical use for above 16 years and even this is not a very long time. This is a promising area because the use of bioresorbable polymer ceramic composites has many advantages. Yokogawa et al., 2002, introduced some biomimetic methods to grow calcium phosphate on chitin scaffolds, phosphorylated chitin fibers or chitosan films. However, no significant mechanical strength improvement has been achieved owing to poor affinity of these organic materials and the heterogeneous distribution of inorganic components (Wang et al., 2001).

Research is focused on the preparation of composites due to the limitations originating from the poor mechanical properties of phase pure dense HA ceramics. In the last years, many reinforcements, including particles (Loku et al. 1990), platelets(Gautier et al. 1999), whiskers, short fibers, metal fibers and dispersoids (De with and Corbijn,1989) and nano-particles (Ahn et al., 2001) have been used to improve the mechanical properties of HA ceramics. The highest reported fracture toughness values were achieved by using 20-30 \% Fe-Cr alloy fibers with $\mathrm{KIC}$ values of $6.0-7.4 \mathrm{MPa}^{1 / 2}$ (Suchanek and Yoshimura, 1998). Biomaterials with improved mechanical properties have been synthesized by the incorporation of hydroxyapatite in composites as a ceramic matrix (Abere et al., 2017).

It's a fact that there is an authentic need for the preparation of highly biocompatible materials that can be utilized in load bearing applications such as artificial tooth roots or artificial bones. A new approach for the preparation of such a material is the use of completely biocompatible non-toxic chitosan/alumina as reinforcements in the HA matrix. Metals generally possess good mechanical properties but show poor biocompatibility, cause stress shielding and release of harmful metal ions causing eventual failure and 
removal of implant. Generally, ceramics possess good biocompatibility but poor fracture toughness and hence, brittleness. Composite materials with engineered interfaces which will combine biocompatibility, mechanical strength and toughness, is the focus of extensive research and this study.

\section{Material and Methods}

The material used for this research are commercial alumina, synthetic chitosan from cowry shells which were purchased from Agbado Oja, Agbado, Ogun State and synthetic hydroxyapatite from limestone. The reagents used in this research are: $\left(\mathrm{NH}_{4}\right) \mathrm{H}_{2} \mathrm{PO}_{4}$ powder $\left(99 \%\right.$ MERCK), $\mathrm{Na}_{2} \mathrm{CO}_{3}$ powder $(99$ $\%$ ALDRICH), potassium hydroxide pellet (99 \% ALDRICH), hydrogen peroxide, oxalic acid powder (99\% ALDRICH), Acetone (Sigma-Aldrich Laborchemickalien GMBH, Seelze, Germany), $\mathrm{HCl}$ and PEG.

\section{Pretreatment operation}

The cowry shells were boiled in an aqueous solution containing 30 volume percent of reagents grade hydrogen peroxide, $\mathrm{H}_{2} \mathrm{O}_{2}$ for 1 hour to remove the organic matter impurities in the shell. It was crushed and ground before subjecting it to sieve size analysis to obtain powder of particle size less than $100 \mu \mathrm{m}$.

\section{Demineralization}

The purpose of demineralization was to remove the mineral matter content of the shell, i.e. $\mathrm{CaCO}_{3}$. The powder was soaked in $0.5 \mathrm{M}$ of $\mathrm{HCI}$ aqueous solution at $25{ }^{\circ} \mathrm{C}$ with a solution to solid ratio of $10 \mathrm{ml} / \mathrm{g}$ for 24 hours to remove the minerals matter. The solution was subjected to filtration technique where the resulting residue was treated with deionized water until a $\mathrm{pH}$ of 7 was obtained. The chitin was oven dried at $105{ }^{\circ} \mathrm{C}$ for 12 hours (Madhavan, 1992).

\section{Deproteinization}

The deproteinization of chitin was carried out by dissolving 1 gram of chitin in $10 \mathrm{ml}$ of $0.5 \mathrm{M}$ potassium hydroxide $(\mathrm{KOH})$. This results in decomposition of the albumen into water soluble amino acids. The solution was filtered while the residue obtained was treated with deionized water until a $\mathrm{pH}$ of 7 was obtained. The product obtained was subsequently sterilized in hot ethanol and oven dried at $105{ }^{\circ} \mathrm{C}$ for 12 hours (Madhavan, 1992).

\section{Deacetylation}

About 1.0 gram of chitin was dissolved in $10 \mathrm{ml}$ of $0.50 \mathrm{M} \mathrm{KOH}$ and boiled for 2 hours on a hot plate at $100{ }^{\circ} \mathrm{C}$ to deacetylate the chitin. The product was cooled to room temperature for 1 hour. It was then filtered and treated 
with deionized water at $60{ }^{\circ} \mathrm{C}$ to retain the solid matter which is chitosan. The prepared chitosan was oven dried at $110^{\circ} \mathrm{C}$ for 24 hours (Madhavan, 1992).

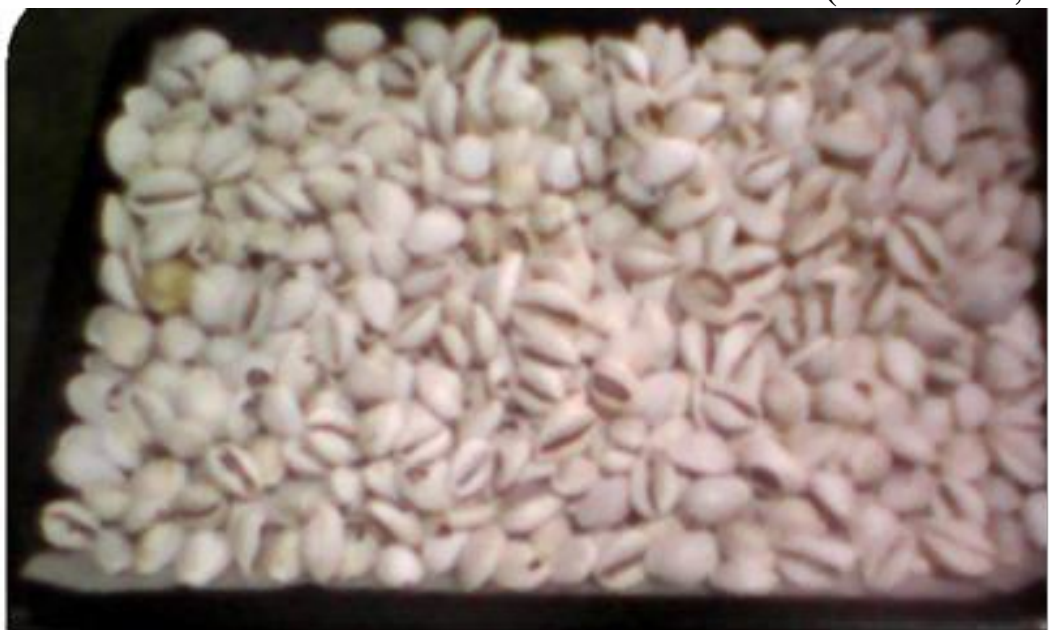

Figure 1: Cowry shells.

\section{Preparation of chitosan nanofiber}

The chitosan was suspended in acetic acid: ethyl acetate: water (40:30:30) by stirring overnight with the magnetic stirrer at $4{ }^{\circ} \mathrm{C}$ to obtain a $12 \%\left(\mathrm{w} . \mathrm{v}^{-1}\right)$ chitosan suspension. The solution was loaded into a $5 \mathrm{ml}$ syringe with a $21 \mathrm{G}$ needle and electrospun at $0.1 \mathrm{ml}^{-1} \mathrm{~h}^{-1}$, under a high electrostatic field $(22 \mathrm{kV})$ onto $12 \mathrm{~mm}$ diameter cover glasses attached on aluminum foil wrapped on a rotating cylinder collector, at $400 \mathrm{rpm}$, placed at a distance of $120 \mathrm{~mm}$ from the needle tip. The procedure was carried out repeatedly. The resulting fiber was dried for 24 hours to get rid of any solvent left on its surface and then collected from the collector.

\section{Synthesis of hydroxyapatite from limestone}

Limestone was also crushed and ground before sieving to obtain sample of particle size less than $100 \mu \mathrm{m} .750 \mathrm{~g}$ of the sample was dissolved in $0.5 \mathrm{M}$ of dilute hydrochloric acid until the reaction stopped to produce carbon dioxide. Insoluble material such as silica was filtered out with filter paper. Oxalic acid was added to the residue to form calcium oxalate as a solid precipitate. The precipitate was treated with deionized water and transferred into a beaker. The calcium oxalate was converted to calcium chloride solution through the addition of dilute $\mathrm{HCl}$. Concentrated sodium carbonate was added to the calcium chloride solution to obtain calcium carbonate precipitate. The precipitate and the residue were separated through filtration technique before the residue was then treated with deionized water. The calcium carbonate was then dried in an ovum at $110{ }^{\circ} \mathrm{C}$ overnight and subjected to heating at $100{ }^{\circ} \mathrm{C}$ to produce calcium oxide $(\mathrm{CaO})$. 
An analytical weighing balance was employed in weighing $79.55 \mathrm{~g}$ of $\mathrm{CaO}$ which was added to $500 \mathrm{ml}$ of deionizer water in a $1000 \mathrm{ml}$ beaker and vigorously stirred at $1000 \mathrm{rpm}$ at the $20{ }^{\circ} \mathrm{C}$ for 24 hours to react and form a suspension of $\mathrm{Ca}(\mathrm{OH})_{2}$ in an excess of deionizer water. The beaker was covered in order to avoid possible contamination through contact with atmospheric conditions. The temperature of the reaction at $20{ }^{\circ} \mathrm{C}$ was kept constant with the aid of a thermostat-controlled water bath. The weighing balance was also used to weigh the quantity of orthophosphoric acid needed. $97.30 \mathrm{~g}$ of $85 \% \mathrm{H}_{3} \mathrm{PO}_{4}$ was added to $\mathrm{Ca}(\mathrm{OH})_{2}$ solution at a rate of $1.5 \mathrm{ml} / \mathrm{min}$. Handheld $\mathrm{pH}$ meter with an accuracy of \pm 0.2 was used to monitor the $\mathrm{pH}$ of the solution when the acid was being added. The reactants were mixed thoroughly for further 24 hours at $1000 \mathrm{rpm}$ to enhance the maturation stage held at the respective reaction temperature of $200{ }^{\circ} \mathrm{C}$. $0.28 \mathrm{~mol}(9.94 \mathrm{~g})$ $\mathrm{NH}_{4} \mathrm{OH}$, was added to the HA slurry after 24 hours ripening period to stabilize the $\mathrm{pH}$ of the super saturation solution to above 9. Assay samples were picked for analysis to determine the chemical composition of mixture in the barrel. A small crucible was filled with a sample of the mixture in the mixing barrel and dried in a drying oven for 1 hour at $110^{\circ} \mathrm{C}$. The samples were transferred into a furnace, sintered at $1200{ }^{\circ} \mathrm{C}$ for 60 minutes and allowed to cool. The samples were emptied from the furnace and ground to powder through motor and pestle.

\section{Preparation of composite of alumina/chitosan nanofiber/nanohydroxyapatite}

Various volume fractions of alumina, chitosan nanofiber and nanohydroxyapatite composites were prepared as indicated in Table $\mathbf{1 .}$

\section{Mechanical characterization of composite}

Different samples of the various volume fractions of the composite were prepared for the mechanical characterization of the composite so as to evaluate the influence of the chitosan nanofiber and alumina on the strength of hydroxyapatite and to determine the volume fraction with the optimum mechanical properties. The following mechanical properties were investigated: the compressive strength, tensile strength, hardness, fracture toughness, modulus of elasticity, and bending strength.

Table 1: Composite volume fractions (\%).

\begin{tabular}{cccc}
\hline Samples & Al & CH & HA \\
\hline 1 & 40 & 30 & 30 \\
2 & 30 & 40 & 30 \\
3 & 20 & 50 & 30 \\
4 & 50 & 20 & 30 \\
5 & 30 & 30 & 40 \\
\hline
\end{tabular}




\begin{tabular}{cccc}
\hline 6 & 20 & 30 & 50 \\
7 & 30 & 20 & 50 \\
8 & 20 & 20 & 60 \\
9 & 30 & 10 & 60 \\
10 & 10 & 30 & 60 \\
11 & 10 & 20 & 70 \\
12 & 20 & 10 & 70 \\
13 & 25 & 5 & 70 \\
\hline
\end{tabular}

\section{Compression test}

The purpose of the compression test was to determine the response of the composite materials under a compressive load. The sample was loaded between two plates before applying a force to the sample through simultaneous movement of the crossheads. During this process, the sample was compressed, and deformation with the corresponding applied load were taken and recorded. The compression test was used in the determination of the compressive strength.

\section{Tensile test}

This was conducted to investigate the response of the materials under axial tensile loading. The sample was fixture into the test apparatus and force was applied to the sample by separating the crossheads of the testing machine. The speed of the crosshead was varied to monitor the rate of strain in the test sample. Data from the test were used to determine tensile strength, modulus of elasticity and bending strength.

\section{Measurement of hardness and fracture toughness}

The hardness and fracture toughness were obtained from the Vickers micro hardness test. The indenter used in this test was a square-based pyramid whose opposite sides intercept at the topmost at an angle of $136^{\circ} .50 \mathrm{~g}$ load was applied for each indentation with a dwell time of 10 seconds. Five indentations were made for each sample but the average was determined and recorded. A calibrated microscope was used to measure the size of the impression. The Vickers hardness number (HV) was evaluated with the application of this formula: $\mathrm{HV}=1.854\left(\mathrm{~F} / \mathrm{D}^{2}\right)$, where $\mathrm{F}$ is the applied force (measured in kilograms-force) and $\mathrm{D}^{2}$ is the area of the indentation (measured in square millimeters).

\section{Elemental analysis of composite}

To characterize the composite's chemical interactions; composite with optimum mechanical properties, 20-20-60 (Al-CH-HA) composite was used for the Fourier Transform Infrared Spectroscopy (FTIR) and the Energy 
Dispersive X-Ray Fluorescence (ED-XRF) analyses. FTIR was used to determine the functional groups and the nature of bond between the composite samples within a range of $4000-500 \mathrm{~cm}^{-1}$ whereas ED-XRF was used to investigate the chemical composition of the composite.

\section{Microstructure characterization}

Scanning electron microscopy was used to examine the surface roughness of the composite samples.

\section{Results and Discussion}

Result obtained from the compressive strength test for the different composite volume fraction is shown in Table 2. Similarly, Table 3 shows the tensile strength obtained for the different composite volume fraction and Table 4 indicates the hardness value of the different volume fractions of the composite. In the same vein, the fracture toughness of the composite with the elastic properties is presented in Tables 5 and 6 respectively while Table 7 shows the bending strength of the different volume fractions of the composite. The chemical composition of the composite is presented in Table 8. The Fourier Transform Infrared Spectroscope for the composite is shown in Figure 2 while Plates 1-3 show the scanning electron micrograph of the composite.

Table 2: Compressive Strength of the composites

\begin{tabular}{|c|c|c|c|c|c|c|c|}
\hline $\mathrm{S} / \mathrm{N}$ & $\begin{array}{l}\text { Al-CH-HA } \\
\text { Composite } \\
\text { volume } \\
\text { fractions }\end{array}$ & I & II & III & IV & V & $\begin{array}{l}\text { Average } \\
\text { Compressive } \\
\text { Strength } \\
\text { (MPa) }\end{array}$ \\
\hline 1 & $40-30-30$ & 148.50 & 156.20 & 161.10 & 165.40 & 151.62 & 156.56 \\
\hline 2 & $30-40-30$ & 164.05 & 158.32 & 153.43 & 160.20 & 159.31 & 159.06 \\
\hline 3 & $20-50-30$ & 163.84 & 167.06 & 161.34 & 168.51 & 160.62 & 164.27 \\
\hline 4 & $50-20-30$ & 158.84 & 169.70 & 170.13 & 162.84 & 172.38 & 166.78 \\
\hline 5 & $30-30-40$ & 173.34 & 162.25 & 165.51 & 169.08 & 167.21 & 167.48 \\
\hline 6 & $20-30-50$ & 175.68 & 171.52 & 168.40 & 162.23 & 170.89 & 169.74 \\
\hline 7 & $30-20-50$ & 176.23 & 169.40 & 177.30 & 170.06 & 168.92 & 172.38 \\
\hline 8 & $20-20-60$ & 174.05 & 178.51 & 187.21 & 183.58 & 185.30 & 181.73 \\
\hline 9 & $30-10-60$ & 173.83 & 170.08 & 178.41 & 180.21 & 175.45 & 175.60 \\
\hline 10 & $10-30-60$ & 169.85 & 178.31 & 172.51 & 176.40 & 175.44 & 174.50 \\
\hline 11 & $10-20-70$ & 171.41 & 173.48 & 168.20 & 178.31 & 170.05 & 172.29 \\
\hline 12 & $20-10-70$ & 168.48 & 171.21 & 165.30 & 169.43 & 172.34 & 169.35 \\
\hline 13 & $25-5-70$ & 156.61 & 168.32 & 163.38 & 160.04 & 159.52 & 161.57 \\
\hline
\end{tabular}


Table 3: Tensile Strength of the composites.

\begin{tabular}{|c|c|c|c|c|c|c|c|}
\hline $\mathrm{S} / \mathrm{N}$ & $\begin{array}{l}\text { Al-CH-HA } \\
\text { Composite } \\
\text { volume } \\
\text { fractions }\end{array}$ & I & II & III & IV & V & $\begin{array}{l}\text { Average } \\
\text { Tensile } \\
\text { Strength } \\
(\mathrm{MPa})\end{array}$ \\
\hline 1 & $40-30-30$ & 121.48 & 134.32 & 125.40 & 129.31 & 120.03 & 126.11 \\
\hline 2 & $30-40-30$ & 124.05 & 122.43 & 136.54 & 128.07 & 127.59 & 127.74 \\
\hline 3 & $20-50-30$ & 125.58 & 130.08 & 138.20 & 135.46 & 128.51 & 131.57 \\
\hline 4 & $50-20-30$ & 131.42 & 128.50 & 133.49 & 137.08 & 133.05 & 132.71 \\
\hline 5 & $30-30-40$ & 129.06 & 135.34 & 133.94 & 138.07 & 130.41 & 133.36 \\
\hline 6 & $20-30-50$ & 134.08 & 141.20 & 138.43 & 132.58 & 144.33 & 138.12 \\
\hline 7 & $30-20-50$ & 157.21 & 164.78 & 177.08 & 175.38 & 165.40 & 167.97 \\
\hline 8 & $20-20-60$ & 168.52 & 171.41 & 183.04 & 175.03 & 165.35 & 172.67 \\
\hline 9 & $30-10-60$ & 172.02 & 163.41 & 167.52 & 170.56 & 173.40 & 169.38 \\
\hline 10 & $10-30-60$ & 168.58 & 171.35 & 165.52 & 163.42 & 160.08 & 165.79 \\
\hline 11 & $10-20-70$ & 157.34 & 161.09 & 167.84 & 158.55 & 165.09 & 161.98 \\
\hline 12 & $20-10-70$ & 160.51 & 162.33 & 156.57 & 157.73 & 160.54 & 159.54 \\
\hline 13 & $25-5-70$ & 145.55 & 151.30 & 143.84 & 154.07 & 140.32 & 147.02 \\
\hline
\end{tabular}

Table 4: Hardness value of the composites.

\begin{tabular}{|c|c|c|c|c|c|c|c|}
\hline $\mathrm{S} / \mathrm{N}$ & $\begin{array}{l}\text { Al-CH- } \\
\text { HA } \\
\text { Composite } \\
\text { volume } \\
\text { fractions }\end{array}$ & I & II & III & IV & V & $\begin{array}{l}\text { Average } \\
\text { Hardness } \\
\text { Value }\end{array}$ \\
\hline 1 & $40-30-30$ & 449.08 & 473.58 & 455.08 & 483.21 & 462.29 & 464.65 \\
\hline 2 & $30-40-30$ & 450.06 & 455.29 & 485.52 & 462.23 & 473.05 & 465.23 \\
\hline 3 & $20-50-30$ & 501.24 & 496.30 & 472.18 & 461.47 & 505.48 & 487.33 \\
\hline 4 & $50-20-30$ & 514.09 & 481.51 & 495.29 & 503.15 & 489.58 & 496.72 \\
\hline 5 & $30-30-40$ & 492.53 & 518.04 & 503.24 & 512.30 & 484.50 & 502.12 \\
\hline 6 & $20-30-50$ & 495.26 & 501.10 & 485.58 & 511.00 & 508.04 & 500.21 \\
\hline 7 & $30-20-50$ & 480.20 & 545.35 & 508.10 & 467.51 & 510.31 & 502.30 \\
\hline 8 & $20-20-60$ & 508.51 & 535.50 & 510.05 & 541.81 & 550.17 & 529.21 \\
\hline 9 & $30-10-60$ & 508.31 & 513.25 & 503.20 & 515.30 & 506.09 & 509.23 \\
\hline 10 & $10-30-60$ & 479.51 & 483.25 & 508.21 & 512.04 & 518.30 & 500.26 \\
\hline 11 & $10-20-70$ & 485.31 & 471.01 & 493.48 & 505.06 & 482.51 & 487.47 \\
\hline 12 & $20-10-70$ & 461.08 & 459.85 & 468.05 & 492.51 & 483.22 & 472.94 \\
\hline 13 & $25-5-70$ & 409.25 & 421.31 & 406.50 & 434.04 & 441.32 & 422.48 \\
\hline
\end{tabular}

Table 5: Fracture toughness of the composites.

\begin{tabular}{llllllll}
\hline S/N & $\begin{array}{l}\text { Al-CH-HA } \\
\text { Composite } \\
\text { volume }\end{array}$ & I & II & III & IV & V & $\begin{array}{l}\text { Average } \\
\text { Fracture } \\
\text { foughness } \\
\text { fractions }\end{array}$ \\
\hline 1 & $40-30-30$ & 4.50 & 4.13 & 4.03 & 3.84 & 3.92 & 4.08 \\
2 & $30-40-30$ & 4.65 & 4.37 & 4.62 & 4.01 & 3.72 & 4.27 \\
3 & $20-50-30$ & 6.08 & 5.94 & 6.21 & 6.04 & 6.01 & 6.06 \\
4 & $50-20-30$ & 6.64 & 6.28 & 5.96 & 5.84 & 6.08 & 6.16 \\
\hline
\end{tabular}




\begin{tabular}{llllllll}
\hline 5 & $30-30-40$ & 6.20 & 5.96 & 6.84 & 6.72 & 6.09 & 6.36 \\
6 & $20-30-50$ & 6.85 & 6.21 & 7.03 & 6.69 & 7.18 & 6.79 \\
7 & $30-20-50$ & 7.81 & 7.02 & 7.31 & 7.05 & 7.10 & 7.26 \\
8 & $20-20-60$ & 7.51 & 7.20 & 7.09 & 7.94 & 7.38 & 7.42 \\
9 & $30-10-60$ & 6.85 & 6.09 & 7.02 & 7.30 & 7.12 & 6.88 \\
10 & $10-30-60$ & 5.91 & 5.28 & 4.94 & 5.33 & 5.21 & 5.33 \\
11 & $10-20-70$ & 3.94 & 3.15 & 4.20 & 4.08 & 4.01 & 3.88 \\
12 & $20-10-70$ & 4.51 & 3.27 & 3.04 & 4.13 & 3.92 & 3.77 \\
13 & $25-5-70$ & 3.88 & 3.51 & 2.96 & 3.04 & 2.61 & 3.20 \\
\hline
\end{tabular}

Table 6: Elastic modulus of the composites.

\begin{tabular}{ccc}
\hline S/N & $\begin{array}{c}\text { Al-CH-HA (composite } \\
\text { volume fractions) }\end{array}$ & $\begin{array}{c}\text { Average elastic modulus } \\
(\mathrm{GPa})\end{array}$ \\
\hline 1 & $40-30-30$ & 2.95 \\
2 & $30-40-30$ & 3.54 \\
3 & $20-50-30$ & 3.85 \\
4 & $50-20-30$ & 4.21 \\
5 & $30-30-40$ & 5.55 \\
6 & $20-30-50$ & 5.99 \\
7 & $30-20-50$ & 6.75 \\
8 & $20-20-60$ & 7.62 \\
9 & $25-15-60$ & 8.23 \\
10 & $15-25-60$ & 6.89 \\
11 & $10-20-70$ & 6.01 \\
12 & $20-10-70$ & 5.73 \\
13 & $25-5-70$ & 3.33 \\
\hline
\end{tabular}

Table 7: Bending strength of the composites.

\begin{tabular}{ccc}
\hline S/N & $\begin{array}{c}\text { Al-CH-HA (composite } \\
\text { volume fractions) }\end{array}$ & $\begin{array}{c}\text { Average bending strength } \\
(\mathrm{MPa})\end{array}$ \\
\hline 1 & $40-30-30$ & 155.80 \\
2 & $30-40-30$ & 157.05 \\
3 & $20-50-30$ & 158.43 \\
4 & $50-20-30$ & 165.31 \\
5 & $30-30-40$ & 166.82 \\
6 & $20-30-50$ & 167.00 \\
7 & $30-20-50$ & 169.93 \\
8 & $20-20-60$ & 171.20 \\
9 & $25-15-60$ & 175.51 \\
10 & $15-25-60$ & 160.35 \\
11 & $10-20-70$ & 156.56 \\
12 & $20-10-70$ & 154.71 \\
13 & $25-5-70$ & 152.55 \\
\hline
\end{tabular}

Table 8: $\mathrm{X}$-Ray Fluorescence analysis of the composite

\begin{tabular}{lllllllllllll}
\hline Elements & $\mathrm{Ca}^{2+}$ & $\mathrm{P}$ & $\mathrm{O}$ & $\mathrm{K}^{+}$ & $\mathrm{Na}^{+}$ & $\mathrm{CO}_{3}^{2-}$ & $\mathrm{Cl}^{-}$ & $\mathrm{F}^{-}$ & $\mathrm{P}_{2} \mathrm{O}_{7}$ & $\mathrm{Mg}^{2+}$ & $\mathrm{Al}^{2+}$ & $\mathrm{Fe}^{2+}$ \\
\hline $\begin{array}{l}\text { Composition } \\
\text { wt }(\%)\end{array}$ & 40.33 & 20.72 & 29.83 & 0.02 & 0.3 & 3.53 & 0.01 & 0.02 & 0.03 & 0.04 & 0.13 & 0.34 \\
\hline
\end{tabular}




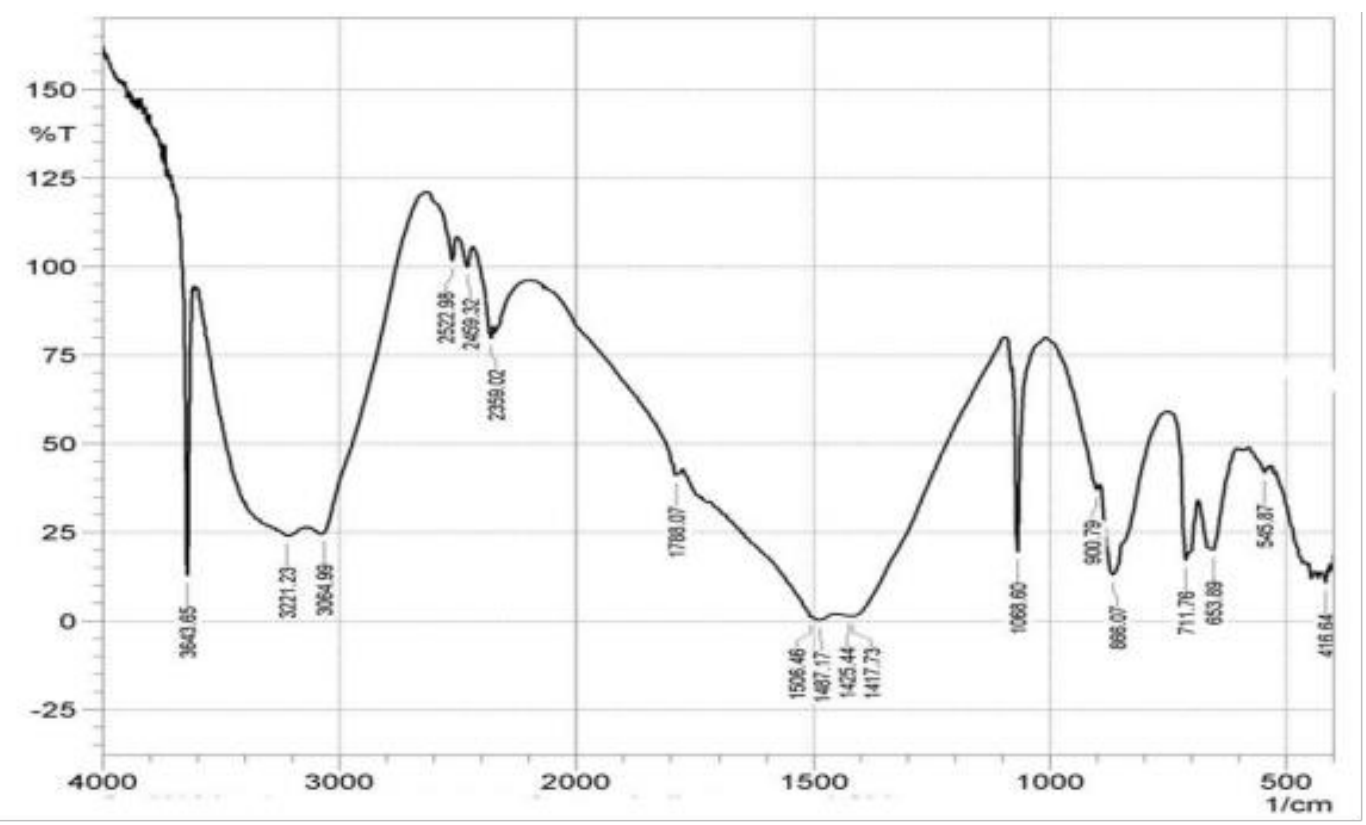

Figure 2: FTIR pattern of the composite

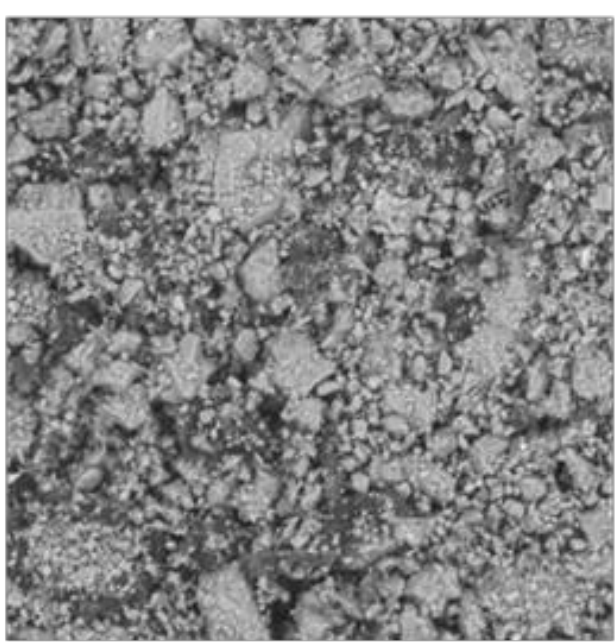

Plate1: SEM image at 750 magnification.

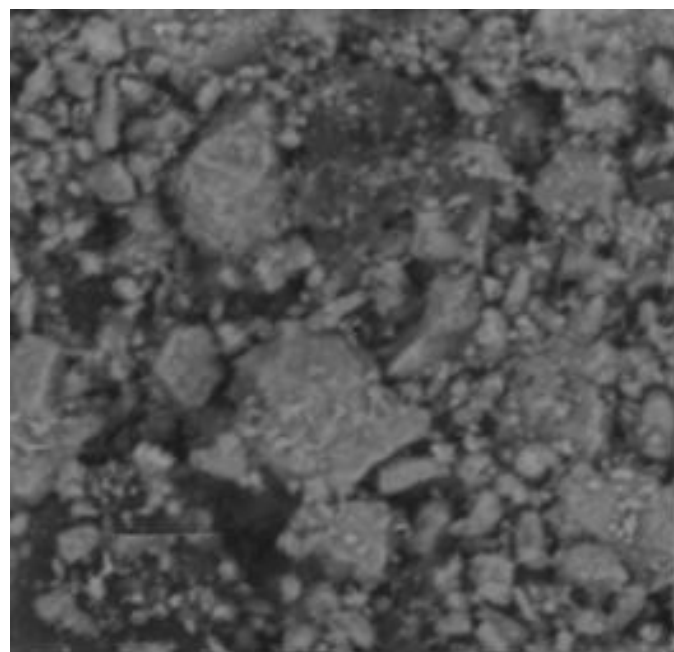

Plate 2: SEM image at 1000 magnification. 


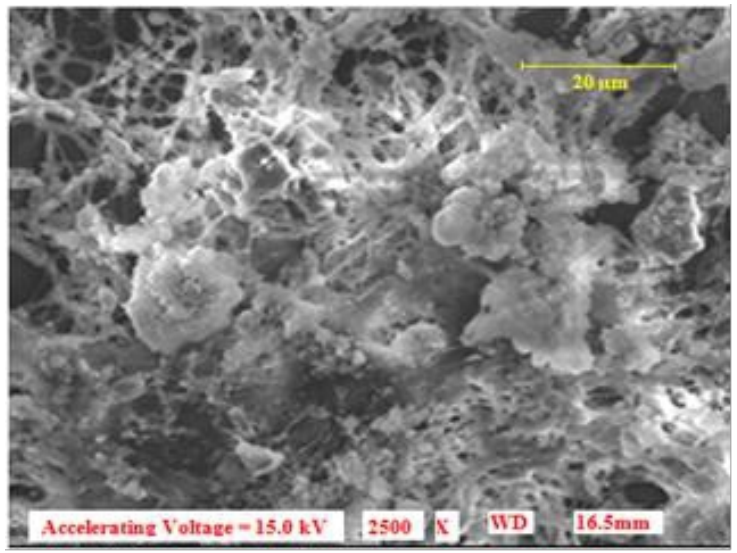

Plate 3: SEM image at 2500 magnification.

\section{Mechanical properties of biomaterials}

Several types of metals and alloys such as stainless steel, titanium, nickel, magnesium, Co-Cr alloys, and Ti alloys; ceramics like zirconia, bioglass, alumina, hydroxyapatite; and polymers such as acrylic, nylon, silicone, polyurethane, polycaprolactone, polyanhydrides are currently being used for load bearing applications (Katti, 2004). The applications include dental replacement and bone joining or replacement for medical and clinical application. Thus, the mechanical properties of biomaterials are very significant. Hydroxyapatite is among the widely investigated bioactive and biocompatible material among them. Hydroxyapatite, even though a suitable substitute material for bone regeneration is limited in its applications due to its brittleness and therefore could not be suitable for load bearing application. The incorporation of alumina and nanofiber of chitosan into the HA matrix has been found to have pronounced effects on the mechanical properties of HA (Li et al., 2002). Increasing the volume fraction of alumina and chitosan (Tables 2-7) had great effect on the mechanical properties of the composite.

\section{Compressive strength of Al-CH-HA composite}

The compressive strength of dense HA is between $500-1000 \mathrm{MPa}$ (Wang et al., 1995; Silva et al., 2000). Increasing volume fraction of chitosan nanofiber in HA matrix had been reported to result in decreasing compressive strength of HA (Abere et al., 2017; Li et al., 2002 and 2005). Hence, the result of this analysis is also observed to follow this trend as increasing volume fraction of $\mathrm{Al}-\mathrm{CH}$ was found to result in corresponding decrease in compressive strength of HA (Table 2). However, at an optimum volume fraction 20-20-60 Al-CH-HA, the compressive strength obtained was 181.73 $\mathrm{MPa}$; after which it was observed that the compressive strength decreased (Table 2). This might be due to the fact that increasing Al-CH volume fraction may have affected the incorporation of the fiber into the matrix leading to 
decrease in adhesion between the matrix and the reinforcement (Abere et al., 2017). The compressive strength of the composite obtained was discovered to be in the range of compact human bone which is $170-193 \mathrm{MPa}$ (Silva et al., 2000).

\section{Tensile strength}

Increasing volume fraction of chitosan nanofiber has been found to increase the tensile strength of the composite (Table 3). The tensile strength of dense HA was reported to be $40-100 \mathrm{MPa}$ (Silva et al., 2000). However, on increasing the volume fraction of the composite, the tensile strength also increased until an optimum composition was reached (Table 3). After the optimum volume fraction of 20-20-60, a decrease in strength was however observed. This might be as a result of decrease in the force of adhesion between the matrix and reinforcement. The volume fraction 20-20-60 composite was found to have a tensile strength of $172.67 \mathrm{MPa}$ and this falls within $50-151 \mathrm{MPa}$ which is the range of the tensile strength of cortical bone (Wang et al., 1995; Ashman et al., 1984; Rho et al., 1998) and tensile strength of compact human bone is $124-174 \mathrm{MPa}$ (Gibson, 1985). Thus, the composite with the optimum composition will be very suitable for load bearing material.

\section{Hardness}

The response of any material when subjected to different conditions of load is determined by its strength and hardness. When a bone or any other material is subjected to external force, there is an internal reaction. The strength of the bone or material can be examined by checking the relationship between the external force and internal reaction that occurs in the material, i.e. load-deformation curve. (Holtrop, 1975). Hardness is among the most prominent mechanical properties of materials when considering the suitability of the materials for biomedical applications. In bone regeneration for example, it is desirable that the hardness of the implants be comparable to that of bone. However, peradventure the hardness of the implant is higher than the bone then it penetrates into the bone (Kokubo, 2008). The hardness of dense hydroxyapatite ranges between 500 to $800 \mathrm{HV}$ (Silva et al., 2000). It was observed that the hardness of the composite synthesized falls within the range of the hardness value of hydroxyapatite but the optimum hardness value obtained is 529.21 at 20-20-60 composite volume fraction (Table 4).

\section{Fracture toughness}

Fracture strength of materials is the maximum stresses which might be endured prior to the occurrence of fracture. The strength of bioceramics is a vital mechanical property because of their brittleness in nature. In brittle 
material, crack easily propagates in tensile load and therefore, it is more critical than compressive load. According to Fischer and Marx, 2002, material with high fracture toughness improved clinical performance and reliability when compare with low fracture toughness material. The fracture toughness of dense hydroxyapatite is approximately $1 \mathrm{MPa}^{1 / 2}$ (Silva et al. 2000) which is far below the fracture toughness of human cortical bone and compact bone which range from $2-12 \mathrm{MPa}^{1 / 2}$ (Kim et al., 2000). Increasing Al-CH volume fraction results to an increase in the fracture toughness of the composite (Table 5). Composite volume fraction 20-20-60 was observed to have the optimal fracture toughness of $7.2 \mathrm{MPa}^{1 / 2}$. This may be as a result of the chemical compatibility of the composite which results in high adhesion force between the matrix and reinforcement. This helps to obtain homogeneous microstructures with the formation of interfaces, which allow the activation of different mechanisms that enable loads to be transferred efficiently and prevent cracking when stressed. Thus composite with volume fraction 20-20-60 (Al-CH-HA), with high fracture toughness will enhance clinical performance and service reliability in load bearing application.

\section{Elastic propriety}

Part of the major problems materials science and engineers working on the improvement of current implant materials is the fact that these biomaterials are generally much stiffer when compared to the human cortical bone. According to the principle of load sharing of the composite theory, when a stiff metal or ceramic implant is implanted in the bone, the bone will be subjected to lower mechanical stresses, and hence the bone will resorb. This is known as "Wolff's Law", i.e., with the varying imposed stress or strain, the bone will remodel so that the stress or strain is retained within specific levels.

Aseptic loosening of the prosthesis with respect to the total hip replacement, due to bone resorption in the proximal femur is as a result of stress and strain in the femoral cortex after the metallic femoral hip replacement is implanted. Elastic attributes of the implant perform a crucial function in permitting the femur to reach a physiologically acceptable state of stress. (Wang et al. 2010) introduced analogue biomaterials in the 1980's so as to prevent the problems of the modulus-mismatch which occur between the bone and biomaterial and also to also enhance the formation of bond between the host tissue and the implant. Several bioactive composite materials have been synthesized and investigated from that time. A synthetic bone substitute should have similar strength to that of the cortical/cancellous bone being replaced (> $200 \mathrm{MPa}$ ). It should also have a similar modulus of elasticity to that of bone $(20 \mathrm{GPa})$ in an attempt to prevent both stress shielding and fatigue fracture under cyclic loading by maintaining adequate toughness (Giannoudis et al. 2005). However, if less than that of bone the load is bore by bone only. 
The elastic propriety of hydroxyapatite is 70-120 GPa (Wang et al., 1995) which is too high and can cause stress shielding that result in loosening of implants in patients with osteoporosis but the incorporation of alumina chitosan nanofiber into the matrix of hydroxyapatite reduced its elastic properties. The composite of volume fraction 25-15-60 (Al-CH-HA) gave the peak value of elasticity (8.23 GPa) (Table 6).

\section{Bending strength}

(Silva, 2000) reported that the bending strength of dense hydroxyapatite is $20-80 \mathrm{MPa}$ whereas the bending strength of human cortical bone is $50-150 \mathrm{MPa}$ (Currey, 1990). The optimum bending strength value of 175.5 MPa was obtained at 25-15-60 composite volume fraction, while 171.20 MPa was obtained at 20-20-60 MPa (Table 7). However, the values of the bending strength of the composite synthesized are in the range of the human cortical bone and hence suitable for bone substitute to prevent stress shielding that result in loosening of implants in patients with osteoporosis. The factors responsible for the mechanical attributes of the composite might result from particle size and particle size distribution of alumina, chitosan, interfacial interactions between the alumina-chitosan nanofiber and HA; and a good distribution of nanofiber in the matrix of HA.

\section{X-Ray Fluorescence analysis of the composite}

The composites have the tendency of being compatible with the human physiological environment. Their biocompatibility is a direct result of their chemical compositions which contain ions commonly found in the physiological environment such as $\mathrm{Ca}^{2+}, \mathrm{K}^{+}, \mathrm{Mg}^{2+}, \mathrm{Na}^{+}, \mathrm{Al}^{2+}$ and of other ions showing very limited toxicity to body tissues (Table 8). Because of their excellent tribological characteristics coupled with their good fracture toughness and reliability, structural ceramics materials like polycrystalline alumina and toughened chitosan hydroxyapatite will find application in hard tissue replacement materials.

\section{FT-IR analysis}

Figure 2 presents the FT-IR spectrum of Al-CH-HA composite. The peak on the band $3643.65 \mathrm{~cm}^{-1}$ is attributed to the $\mathrm{OH} \cdots \mathrm{O}$ stretching vibration and N-H band which lies between $3221.23 \mathrm{~cm}^{-1}$ and $3064.99 \mathrm{~cm}^{-1}$ shows the intermolecular hydrogen bonding of the chitosan polymer molecules (Li et al, 2006; Wan et al, 2009). The peaks at $2522.98 \mathrm{~cm}^{-1}, 2459.32 \mathrm{~cm}^{-1}$, and 2359.02 $\mathrm{cm}^{-1}$ can be attributed to the primary amine $-\mathrm{NH}_{2}$ and secondary amine absorption band respectively (IR correlation chart). Three peaks at 1487.17 $\mathrm{cm}^{-1}, 1425.44 \mathrm{~cm}^{-1}, 1417.73 \mathrm{~cm}^{-1}$ assigned to the deformation of $\mathrm{C}-\mathrm{CH}_{3}$ band and the band $1506.46 \mathrm{~cm}^{-1}$ may be attributed to the carbonyl $\mathrm{C}=\mathrm{O}-\mathrm{NHR}$ band 
(Wan et al, 2009). At $1068.60 \mathrm{~cm}^{-1}$ is attributed to skeletal vibration involving C-O stretching.

\section{Microstructure analysis}

The dispersion of the reinforcement in the matrix is another crucial factor that determines the mechanical attributes of composites. The dispersion of the fiber in the matrix of the synthesized composite was studied for the 2020-60 Al-CH-HA volume fraction, being the fraction with optimum properties. In Plates $\mathbf{1}$ and 2, the SEM images taken at a magnification of 750 and $1000 \mathrm{x}$ respectively show the dispersion of the reinforcement, the chitosan nanofiber, in the matrix HA. However, at a higher magnification of $2500 \mathrm{x}$ as in Plate 3, the dispersion of the fiber in the matrix of HA becomes very visible. The chemical interactions and compatibility which exist between the components of the composite help to obtain the homogeneous microstructures which results in strong bond strength between the phases. The chemical interactions between the $-\mathrm{NH}_{2}$ group and primary and secondary - $\mathrm{OH}$ group of $\mathrm{CH}$ reinforcement fiber with the ionic bond in $\mathrm{Ca}^{2+}$ of $\mathrm{HA}$ matrix resulted in high adhesion between $\mathrm{CH}$ and $\mathrm{HA}$, which enable the matrix to hold the $\mathrm{CH}$ fiber together and transfer the applying load to the reinforcement fiber, consequently, improving the strength of Al-CH-HA composite (Yamaguchi et al., 2001). The incorporation of $\mathrm{CH}$ fiber into the HA matrix results in good mechanical property of the composite which cannot be attained by any of the constituents alone.

\section{Conclusion}

Al-CH-HA composite was successfully synthesized with the 20-20-60 being the optimum volume fraction. Increasing volume fractions of aluminachitosan nanofiber in the matrix of HA decreased the compressive strength (181.73 MPa), hardness (529.21 HV) and elastic modulus $(8.23 \mathrm{GPa})$ of HA while its tensile strength $(172.67 \mathrm{MPa})$, bending strength $(175.51 \mathrm{MPa})$ and

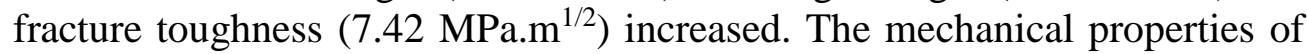
the composite synthesized this work is similar to the mechanical properties of the human cancellous and cortical bone. Consequently, the material will be a suitable candidate for load bearing applications. X-Ray Fluorescence analysis result indicates that their chemical compositions contain ions which are found in the physiological environment. In addition, the SEM micrograph revealed the dispersion of the alumina-chitosan fiber in the matrix of hydroxyapatite. The chemical compatibility and the interactions between the constituents of the composite were revealed by the FT-IR result and may be responsible for the microstructure obtained with the formation of interfaces which enhance the activation of different mechanisms that improve the mechanical strength of hydroxyapatite. Thus, the improvement of the mechanical property of HA 
was achieved through the strengthening of hydroxyapatite with aluminachitosan nanofiber with enhanced usefulness in load bearing application.

\section{References:}

1. Abere D.V., Oyatogun G. M., Akinwole I.E.,, Abioye A.A., Rominiyi A.L., Igbonwelundu M. T. (2017). Effects of increasing chitosan nanofibre volume fraction on the mechanical property of hydroxyapatite. Amer. J. Mater. Sci. Engin., 5 (1), 6-16.

2. Ashman R. B., Guo A., Hasting L. (1984). A continuous wave technique for the measurement of the elastic points of cortical bone. $\mathrm{J}$. Biomech. 17 (5), 349-361.

3. Currey J.D. (1990). Physical characteristics affecting the tensile failure property of compact bone. J. Biomech. 23, 837-844.

4. De With G., Corbijn A.J., (1989). "Metal fibre reinforced $H A$ ceramics. J. Mater. Sci., 24, 3411-3415.

5. Fischer, H., \& Marx, R. (2002). Fracture toughness of dental ceramics: Comparison of bending and indentation method. Dent. Mater. 18 (1), 12-19.

6. Gautier S., West J.L., Champion E., (1999). Rheological characteristics of alumina platelet-HA composite suspensions. J. Europ. Ceram. Soc. 19, 469-477.

7. Giannoudis, P.V., Dinopoulos, H., Tsiridis, E., (2005). Bone substitutes: An update, injury. , Int. J. Care Injured. 365, 20-27.

8. Jayachandran V., \& Se-Kwon K., (2010). Chitosan composites for bone tissue engineering-An overview. J. Mar. Drugs. , 8, 2252-2266.

9. Katti, K.S., (2004). Biomaterials in total joint replacement. Colloid. Surf. B: Biointerf. 39 (3), 133-142.

10. Kim H.M., Sasaki Y., Suzuki S. (2000). Mechanical property of bioactive ceramics and cancellous bones. J. Bioceram. 6, 45-48.

11. Kokubo, T. (2008). Bioceramics and their clinical applications. Bioceram. 13, 227-230.

12. Langer R., Tirrell D.A., Kumar M. N., (2004). Toughening of alumina/zirconia ceramic composites with silver particles. J. Eur. Ceram. Soc. 22, 2165- 2168.

13. Li B., Hu Q., Qian X., Fang Z., Shen J., (2002). Bioabsorbable chitosan/hydroxyapatite composite rod for internal fixation of bone fracture prepared by in situ precipitation. Acta. Polym. Sin. 6, 828833.

14. Li Q., Chen Z., Darvell B., Zeng Q., Li G., Ou G., Wu M., (2006). Biomimetic synthesis of the composites of hydroxyapatite and chitosan-phosphorylated chitosan polyelectrolyte complex. Mater. Lett. 60, 3533-3536. 
15. Li Q., Wu M., Tang L., (2008). Bioactivity of a novel nano composite of hydroxyapatite and chitosan phosphorylated chitosan polyelectrolyte complex. J. Bioact. Compat. Polym., 23, 520-535.

16. Li Z., Yubao L., Aiping Y., Xuelin P., Xuejiang W., Xiang, Z., (2005). Preparation and in vitro investigation of chitosan/nanohydroxyapatite composite used as bone substitute materials. J. Mater. Sci. Mater. Med. 16, 213-219.

17. Loku K., Yoshimura M., Somia S., (1990). Microstructure and mechanical properties of HA ceramics with zirconia dispersion prepared by post-sintering. Biomater. 11, 57-61.

18. Luo X. L., Xu J. J., Wang J. L., Chen H. Y., (2005). Chitosan composite. Chem. Commun., 21, 69-72.

19. Madhavan P.X., (1992). Scaffolds for tissue fabrication: Chitin chitosan and their novel applications. Science Lecture Series, CIFT, Kochi.

20. Madhavan P., Nair K., (1974). Utilization of prawn waste: Isolation of chitin and its conversion to chitosan. Fish. Technol., 50-53.

21. Park S.B., You J.O., Park H.Y., Haam S.J., Kim W.S., (2001). Biomaterials. Park ed. 22. France.

22. Ratner B.D., Hoffman A.S., Schoen F.J., Lemons J.E., (2004). Biomaterials science, an introduction to materials in medicine, $2^{\text {nd }}$ edition" Elsevier Academic Press, San Diego, pp.162.

23. Rho J.Y., Kuhn-Spearing, Zioupos P., (1998). Mechanical property and the hierarchical structure of bone, Med. Eng. Phys. 20, 99-102.

24. Shahidi, F. Abuzaytoun, R. (2005). Chitin, chitosan, and co products: Chemistry, production, applications, and health effects. Adv. Food Nutr. Res., 49, 93-135.

25. Silva V.V., Lameiras F.S., Domingues R.Z. (2000). Microstructural and mechanical properties of bioceramics. J. Biomed. Mater. Res. $54,139-148$.

26. Sono A., (2003). Synthesis of nano-hydroxyapatite. J. Biomed. Res. 3 , 34-39.

27. Suchanek W., \& Yoshimura, M., (1997). Processing and properties of hydroxyapatite- based biomaterials for use as hard tissue replacement implants., J. Mater. Res. 13 (1), 94-117.

28. Suzuki T., Matsumoto T., Hagino Y., (1998). Science and technology of polymers and advanced materials (Eds: P. N. Prasad, J. E. Mark, S. H. VandeVord P. J., Matthew H. W., De Silva S.P., Mayton L. Wu B., Wooley P. H., (2002). Property and Applications of Chitosan". J. Biomed. Mater. Res. 59, 585.

29. Wang H., Li Y., Zuo Y., Li J., Ma S., Cheng L., (2010). Biocompatibility and osteogenesis of biomimetic nano- 
hydroxyapatite/polyamide composite scaffolds for bone tissue engineering. Biomater. 28 3338-3348.

30. Wang, R.Z., Cui, F.Z., Lu, H.B., Wen, H.B., Ma, C.L., Li, H.D., (1995). Synthesis of nanophase hydroxyapatite/collagen composite. J. Mater. Sci. Lett. 14 (7), 490-492.

31. Wang X., Ma, J., Wang Y., He B., (2001). Structural characterization of phosphorylated chitosan and their applications as effective additives of calcium phosphate cements. Biomater. 22, 2247-2255.

32. Wang X., Tan Y., Zhang B., Gu Z., Li X., (2009). Synthesis and evaluation of collagen chitosan hydroxyapatite nanocomposites for bone grafting. J. Biomed. Mater. Res. Part A 89, 1079-1087.

33. Yamaguchi I., Tokuchi K., Fukuzaki H., Koyama Y., Takakuda K., Monma H., Tanaka J. (2001). Preparation and microstructure analysis of chitosan/hydroxyapatite nanocomposites. J. Biomed. Mater. Res. $55,20-27$.

34. Yokoyama A., Yamamoto S., Kawasaki T., Kohgo T., Nakasu, M., (2002). Development of calcium phosphate cements using chitosan and citric acid for bone substitute materials. Biomater. 23, 1091-1101. 